\title{
Thermodynamic Analysis of ZnO Crystal Growth from the Melt
}

\section{Morteza Asadian}

Iranian National Center of Laser Science and Technology, Tehran, Iran.

Email: morteza169@yahoo.com,morteza.asadian@gmail.com

Received March 11 ${ }^{\text {th }}, 2012$; revised April 12 $2^{\text {th }}, 2012$; accepted April 20 ${ }^{\text {th }}, 2012$

Copyright (C) 2013 Morteza Asadian. This is an open access article distributed under the Creative Commons Attribution License, which permits unrestricted use, distribution, and reproduction in any medium, provided the original work is properly cited.

\begin{abstract}
Recently, the efforts in solid-state materials include developing technologies capable of producing $\mathrm{ZnO}$ wafers in large dimensions and good quality based device applications. High quality bulk crystals are obtained by growing from high purity the melt. However, the thermochemical properties of $\mathrm{ZnO}$ (high melting point and high vapor pressure) make the growth of single crystals difficult. The thermodynamic calculations show that $\mathrm{ZnO}$ crystals can be grown from the melt if a suitable dynamic atmosphere composition is used. The oxygen requirement with increasing the temperature can be fulfilled by adding the NO-NO 2 gases into the $\mathrm{CO}_{2}$ atmosphere. At $\mathrm{ZnO}$ melting point, the oxygen partial pressure of gas mixtures containing $\mathrm{CO}_{2}-\mathrm{NO}-\mathrm{CO}-\mathrm{NO}_{2}$ at $\mathrm{Pt}=5 \mathrm{~atm}$ reaches to $\mathrm{PO}_{2}=0.29 \mathrm{~atm}$. According to this new thermodynamic result, it would be expected that $\mathrm{ZnO}$ crystal could be grown from the melt at lower total pressure comparing to pure $\mathrm{CO}_{2}$.
\end{abstract}

Keywords: ZnO Crystal; Thermodynamic Calculation; Phase Equilibria; Growth Atmosphere

\section{Introduction}

Owing to their short-wavelength and high-power frequency properties, wide-band-gap semiconductor materials such as $\mathrm{GaN}$ [1], $\mathrm{SiC}$ [2], and $\mathrm{ZnO}$ [3] have been attended for variety of optoelectronics and microelectronics application. These properties combined with good thermal conductivity and stability which makes them as attractive materials for higher temperatures, higher power densities and higher voltages to utilize in future electrooptic systems [4].

Zinc oxide belongs into II-VI semiconductors group that most commonly exhibits hexagonal (wurtzite) crystal structure with $\mathrm{a}=3.25 \mathrm{~A}$ and $\mathrm{c}=5.12 \mathrm{~A}$ in its unstrained phase [5]. Wurtzite crystals can be cleaved cleanly along several different planes. The c-plane (0001) intercepts only the z-axis and in the case of zinc oxide produces polar surfaces because of the lack of inversion symmetry along the c axis [6]. Furthermore, because of its wurtzite crystal structure and lattice parameter $(\mathrm{a}=$ $3.25 \mathrm{~A}$ in the a-direction) $\mathrm{ZnO}$ is isomorphous with $\mathrm{GaN}$ and has potential to be used as a substrate material for GaN-based epitaxial devices [7]. In contrast to GaN, it has a large exciton binding energy of $60 \mathrm{meV}$ and, as a result, its stimulated emission and lasing have been ob- served from room temperature up to $550 \mathrm{~K}$ [8]. This means that $\mathrm{ZnO}$ excitons will remain bounded at high temperatures and guarantees more efficient exciton emission at higher temperatures compared with other wide band gap materials [9].

$\mathrm{ZnO}$ has a high melting point $\left(\mathrm{T}_{\mathrm{m}}=2248 \mathrm{~K}\right)$, and decomposes rapidly at temperatures above $1650 \mathrm{~K}$, which is difficult to achieve bulk crystal growth [10]. Attempts are made to grow $\mathrm{ZnO}$ in a variety of methods. Its bulk crystal can be grown from the melt [11], hydrothermal [12] and vapor phase growth techniques [13].

Although $\mathrm{ZnO}$ single crystals are successfully grown from alkaline hydrothermal solutions and wafers with good crystalline quality are commercially obtained [14], solvent inclusions are always incorporated and hydrogen and lithium contaminants into the crystal are high [15]. Furthermore, the growth rate of $\mathrm{ZnO}$ crystal is typically low, in the order of $0.5-1 \mathrm{~mm}$ per day [16]. On the other hand, the suitability of $\mathrm{ZnO}$ crystals for epitaxy strongly depends on the surface preparation and subsequent characterization [17]. Therefore, attempts have recently been made to grow single crystal bulks from the melt.

Single crystals of $\mathrm{ZnO}$ can be grown from the melt at high oxygen pressures and temperatures. The Czochralski [11] and Bridgman [18] methods are the most com- 
mon melt-growth techniques used for production of the bulk single-crystals. The advantages of the Czochralski and Bridgman methods are relatively high growth rates (in the range of several millimeters per hour) and the nearly thermodynamic equilibrium conditions capable to generate bulk crystals of high structural perfection.

In the case of $\mathrm{ZnO}$, a major problem is finding a suitable crucible, which can work at the high melting point and high vapor pressure of this material. Under these conditions, most crucible materials will either melt or oxidize, contaminating the $\mathrm{ZnO}$ melt. Nause [19] worked on a cold crucible to dominate the drawback. In the cold crucible method, also known as skull crucible, the melt is contained in a thin solid shell of the same composition as the growth material. However this growth method results in a large temperature gradient from the shell (which must be kept cold and solid) through to the melt which must be kept hot and liquid. This large thermal gradient results in a higher concentration of dislocation defects and limits the maximum size of the crystals.

In this article, thermodynamic considerations on the possibility of the $\mathrm{ZnO}$ crystal growth from the melt in iridium crucible are presented. The paper is mainly focused on applying suitable operating parameters to hold $\mathrm{ZnO}$ melt stable during the growth process and to suppress the oxidation of iridium crucible.

\section{Thermodynamic Background}

The general redox equilibrium reaction can be expressed by

$$
\mathrm{aM}_{\mathrm{x}} \mathrm{O}_{\mathrm{y}} \leftrightarrow \mathrm{bM}_{\mathrm{z}} \mathrm{O}_{\mathrm{w}}+1 / 2 \mathrm{O}_{2}
$$

Standard Gibbs free energy for the above chemical reaction can be defined as function of temperature:

$$
\Delta \mathrm{G}^{\circ}=\Delta \mathrm{H}^{\circ}-\mathrm{T} \Delta \mathrm{S}^{\circ}=-\mathrm{RT} \operatorname{Ln}(k)
$$

$\Delta \mathrm{H}^{\circ}$ is the standard enthalpy change and $\Delta \mathrm{S}^{\circ}$ is the standard entropy change for the reaction. $\mathrm{R}$ is the universal gas constant and $\mathrm{T}$ refers to the absolute temperature. The equilibrium constant $(k)$ gives the required combination of the activities of the reactants as

$$
k=\left(\frac{a_{\mathrm{M}_{\mathrm{z}} \mathrm{O}_{\mathrm{w}}}^{\mathrm{b}} \times P_{\mathrm{O}_{2}}^{1 / 2}}{a_{\mathrm{M}_{\mathrm{x}} \mathrm{O}_{\mathrm{y}}}^{\mathrm{a}}}\right) .
$$

The activity of materials (element and its oxide) in their standard state has values of unity for pure solid in Equation (2). For gaseous species, the activity of materials in the gas phase is equal to its partial pressure (assuming ideal behavior of the gas) [20].

For the oxidation of a mole material, oxidation from the $\mathrm{m}$ valent state to the $\mathrm{m}-\mathrm{n}$ valent state proceeds under the consumption of $(\mathrm{n} / 2)$ dn mole oxygen. Herein $\mathrm{m}=$ $2 \mathrm{y} / \mathrm{x}$ and $\mathrm{n}=2 / \mathrm{ax}$. $\mathrm{m}$ valent gives a number between $1-8$ and always $m \geq n$. Table 1 indicates four possible conditions of the redox equilibrium reactions obtained with simplifying the Equation (1).

The reaction equilibrium would take place between pure material $\mathrm{M}$, its oxide and oxygen gas in the case $\mathrm{m}$ $=\mathrm{n}$. In such a case, $\Delta \mathrm{G}$ is a linear function of temperature and a plot of $\Delta \mathrm{G}=\mathrm{RT} \log \left(\mathrm{PO}_{2}\right)$ versus temperature gives the lines for each oxidation reaction on an Ellingham diagram [21]. These lines separate phase regions when an oxidation state overcomes and the whole graph represents a predominance phase diagram for the material $\mathrm{M}$ and its oxides. Thermodynamic data are taken from [22] throughout this paper.

\section{Melt ZnO Crystal Growth}

There are technical obstacles to the growth of single crystal $\mathrm{ZnO}$ from the melt. The triple point of $\mathrm{ZnO}$ (the temperature and pressure at which all three phases of the substance, including gas, liquid and solid, coexist in thermodynamic equilibrium) is $2248 \mathrm{~K}$ under the total $\left(\mathrm{Zn}\right.$ and $\mathrm{O}_{2}$ ) vapor pressure of $1.06 \mathrm{~atm}$. Figures 1 and 2 show the predominance diagram in the corresponding temperature range of the $\mathrm{Zn}-\mathrm{O}$ system at total pressures of 1 and $5 \mathrm{~atm}$. As it can be inferred from Figure 1, be fore the melting point, $\mathrm{ZnO}$ evaporates under dissociation

$$
\mathrm{ZnO}(\mathrm{s})=\mathrm{Zn}(\mathrm{g})+1 / 2 \mathrm{O}_{2}
$$

which has strongly impeded the development of bulk

Table 1. Different conditions of redox equilibrium reaction.

\begin{tabular}{ccc}
\hline $\mathrm{m}$ & $\mathrm{s}$ & The redox equilibrium reaction \\
\hline even & even & $2 \mathrm{MO}_{(\mathrm{m} / 2)} \leftrightarrow 2 \mathrm{MO}_{(\mathrm{m}-\mathrm{n}) / 2}+(\mathrm{n} / 2) \mathrm{O}_{2}$ \\
even & odd & $2 \mathrm{MO}_{(\mathrm{m} / 2)} \leftrightarrow \mathrm{M}_{2} \mathrm{O}_{(\mathrm{m}-\mathrm{n})}+(\mathrm{n} / 2) \mathrm{O}_{2}$ \\
odd & even & $\mathrm{M}_{2} \mathrm{O}_{\mathrm{m}} \leftrightarrow \mathrm{M}_{2} \mathrm{O}_{(\mathrm{m}-\mathrm{n})}+(\mathrm{n} / 2) \mathrm{O}_{2}$ \\
odd & odd & $\mathrm{M}_{2} \mathrm{O}_{\mathrm{m}} \leftrightarrow 2 \mathrm{MO}_{(\mathrm{m}-\mathrm{n}) / 2}+(\mathrm{n} / 2) \mathrm{O}_{2}$ \\
\hline
\end{tabular}

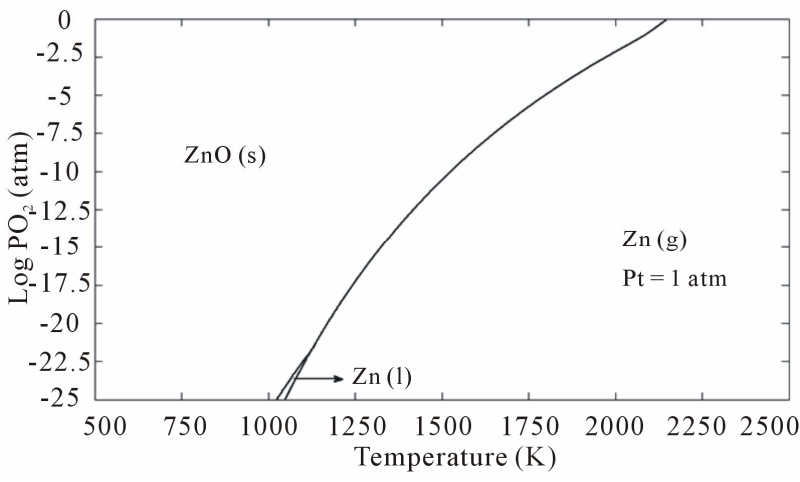

Figure 1. Predominance diagram for $\mathrm{Zn}$ and its oxide $\mathrm{ZnO}$ in dependence on $\mathrm{T}$ and the oxygen pressure $\mathrm{PO}_{2}$ at total pressure of $1 \mathrm{~atm}$. 


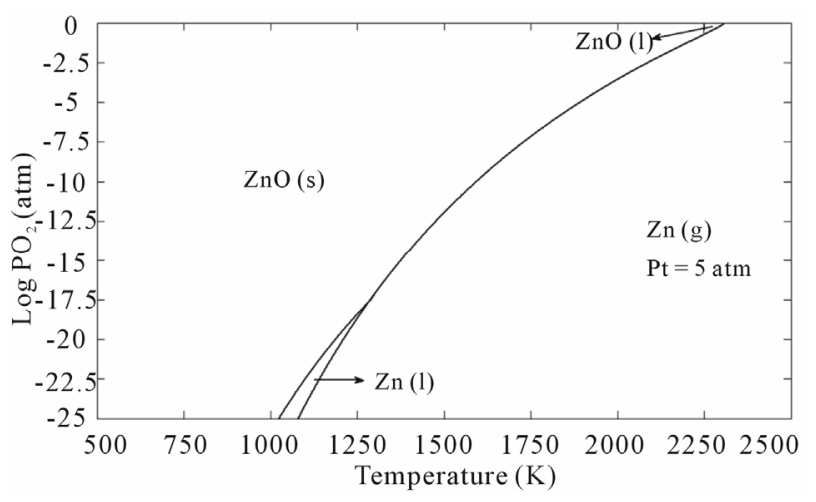

Figure 2. Predominance diagram for $\mathrm{Zn}$ and its oxide $\mathrm{ZnO}$ in dependence on $\mathrm{T}$ and the oxygen pressure $\mathrm{PO}_{2}$ at total pressure of 5 atm.

crystal growth from the melt. To maintain the $\mathrm{ZnO}$ melt stable, the total pressure of oxygen-containing atmosphere in the growth chamber must be considerably larger than $1.06 \mathrm{~atm}$.

\section{Iridium Crucible}

Due to the volatilization of $\mathrm{ZnO}$ oxide melt and the necessity of an oxidizing atmosphere, the crucible that contains the melt should consist of a noble metal. Platinum group of metals and their alloys are the only materials recognized to have high temperature chemical stability, oxidation resistance and resistance to react with many molten oxides. Although growth from platinum crucibles can be performed in oxygen presence, platinum does not appear to be widely used for the growth of oxide materials, probably due to its relatively low melting point (2042 $\mathrm{K}$ ) in comparison with that for most refractory oxides or mixtures of oxides.

Owing to its high melting point and high mechanical strength even at $\mathrm{T}>2250 \mathrm{~K}$, iridium is particularly a suitable material for applications in which preclude the use of platinum alloys or rhodium such as the stressrupture strength, creep behavior and thermal shock [23]. An important application of iridium is its utilization as crucible for pulling refractory oxide crystals such as GGG $\left(\mathrm{T}_{\mathrm{m}}=2023 \mathrm{~K}\right)$ [24] and $\mathrm{ZnO}\left(\mathrm{T}_{\mathrm{m}}=2248 \mathrm{~K}\right)$ [18].

It is worthy to mention that iridium crucibles are sensitive to oxygen, especially at the medium temperatures $(\sim 870-1000 \mathrm{~K})$ at which the metal would be oxidized to solid iridium oxide. $\mathrm{IrO}_{2}$ (s) decomposes to iridium metal at temperatures higher than $1370 \mathrm{~K}$ according to the Equation

$$
\mathrm{IrO}_{2}(\mathrm{~s})=\mathrm{Ir}(\mathrm{s})+\mathrm{O}_{2}
$$

As illustrated in Figure 3, if oxygen is applied at temperatures higher than $1370 \mathrm{~K}$, iridium parts will not be oxidized. A solution could be tried by heating the growth set up in $\mathrm{N}_{2}$ or Ar protective gas (like that used for GGG crystal growth [25]) up to $1400-1500 \mathrm{~K}$ in an oxygen free atmosphere and then adding $1 \%-2 \% \mathrm{O}_{2}$ into the system. However, practically this is not a solution for the problem because of serious sublimation of zinc oxide at $\mathrm{T}<1500 \mathrm{~K}$.

The stability regions for $\mathrm{Zn}$ and $\mathrm{Ir}$ and their oxides versus temperature and the $\mathrm{Zn}$ partial pressure $\mathrm{P}_{\mathrm{Zn}}$ are depicted in Figure 4. It can be seen that at the $\mathrm{ZnO}$ melting point $\left(\mathrm{T}_{\mathrm{m}}=2248 \mathrm{~K}\right)$ the partial pressure of $\mathrm{Zn}$ at $\mathrm{Pt}=$ 5 atm should be more than 0.108 atm to have $\operatorname{Ir}(\mathrm{s})+\mathrm{ZnO}$ (1) desired phase. From Figure 4, it seems reasonable to add an amount of metallic zinc into the starting material in order to reduce the evaporated zinc oxide during the growth. Because of the low boiling point of $\mathrm{Zn}\left(\mathrm{T}_{\mathrm{b}}=\right.$ $1179 \mathrm{~K})$, the required partial pressure of zinc can supply into growth atmosphere before the evaporated of $\mathrm{ZnO}$ becomes serious.

However, the metallic zinc may easily alloy with construction parts especially iridium crucible. Although, the phase diagram of $\mathrm{Zn}$-Ir is still unpublished, at least three intermetallic compounds such as $\operatorname{Ir}_{2} Z_{11}, \operatorname{IrZn}_{3}$, and $\mathrm{Ir}_{7} \mathrm{Zn}_{19}$ have been reported [26]. The formation of $\mathrm{Ir}-\mathrm{Zn}$ alloys can severely destroy the iridium crucible. More over, they cause iridium come into the melt and con-

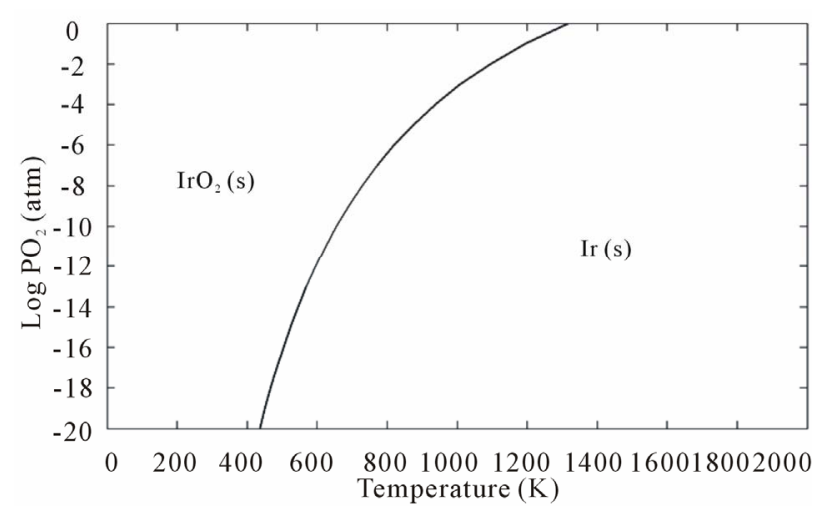

Figure 3. Predominance diagram for $\operatorname{Ir}$ and $\operatorname{IrO}_{2}(\mathrm{~s})$ in the Temperature- $\mathrm{PO}_{2}$ plane.

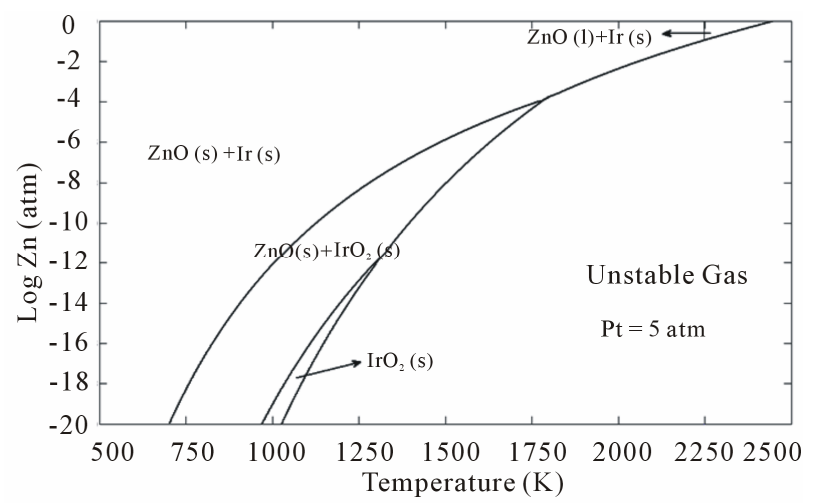

Figure 4. The predominance diagram for $\mathrm{Zn}$ and $\mathrm{Ir}$ and their oxides versus the temperature and $\mathbf{P}_{\mathrm{Zn}}$. 
taminate the grown crystal.

\section{Growth Atmosphere}

The growth atmosphere of oxides crystal should have two conditions.

1) Considering a type of oxide material listed in Table 1, the following reaction holds:

$$
\mathrm{Me}_{2} \mathrm{O}_{\mathrm{m}}(\mathrm{s}, 1) \leftrightarrow \mathrm{Me}_{2} \mathrm{O}_{(\mathrm{m}-\mathrm{n})}(\mathrm{s}, 1, \mathrm{~g})+(\mathrm{n} / 2) \mathrm{O}_{2}
$$

The oxygen partial pressure must be in a range in which the favored valency of the oxide material $\left(\mathrm{Me}_{2} \mathrm{O}_{\mathrm{m}}\right)$ is stable. Often $\mathrm{PO}_{2}$ should be more than $\left(\mathrm{PO}_{2}\right)_{\min }$. Herein $\left(\mathrm{PO}_{2}\right)_{\text {min }}$ is the minimum partial pressure of $\mathrm{O}_{2}$ where the reaction (5) moves to the left side for the given growth temperature $\left(\left(\mathrm{PO}_{2}\right)_{\mathrm{eq}}>\left(\mathrm{PO}_{2}\right)_{\mathrm{min}}\right)$.

2) The reaction equilibrium between a pure solid construction material $\mathrm{M}$, its pure oxide and oxygen gas is given as:

$$
2 \mathrm{M}(\mathrm{s})+(\mathrm{m} / 2) \mathrm{O}_{2}(\mathrm{~s}, 1) \leftrightarrow 2 \mathrm{MO}_{(\mathrm{m} / 2)}(\mathrm{s}, \mathrm{g})
$$

The oxygen partial pressure should be low enough to avoid oxidation of construction parts (crucible, seed holder) being in contact with the melt. Herein $\mathrm{PO}_{2}$ should be less than $\left(\mathrm{PO}_{2}\right)_{\max }$, the partial pressure in which the construction material is in equilibrium with its oxide in the $\mathrm{m}$ valency state $\left(\left(\mathrm{PO}_{2}\right)_{\max }>\left(\mathrm{PO}_{2}\right)_{\mathrm{eq}}\right)$. Because the oxide construction parts are often stable at rather low temperatures and oxide crystal almost decompose at high temperatures, both conditions are accomplished if $\left(\mathrm{PO}_{2}\right)_{\min }<\left(\mathrm{PO}_{2}\right)_{\mathrm{eq}}<\left(\mathrm{PO}_{2}\right)_{\max }$. Commonly, amounts of oxygen, $1-2 \mathrm{vol} \%$ [27] in the case of GGG growth, are added into the growth atmosphere to prevent volatile oxides. However, this value $\left(\mathrm{PO}_{2}\right)$ often is more than $\left(\mathrm{PO}_{2}\right)_{\max }$ at lower temperatures. Therefore, it leads to oxidation of the construction material.

A solution to this problem is that mixtures containing an oxygen bearing gas like $\mathrm{CO}_{2}$ are utilized in the growth atmosphere. They produce a temperature dependent oxygen partial pressure in away that the $\mathrm{O}_{2}$ partial pressure increases with temperature and oxidation of construction parts decreases accordingly.

\section{1. $\mathrm{CO}_{2}-\mathrm{CO}$ System}

$\mathrm{CO}_{2}$ decomposes into $\mathrm{CO}$ and $\mathrm{O}_{2}$ with increasing the temperature according to

$$
2 \mathrm{CO}_{2}=2 \mathrm{CO}+\mathrm{O}_{2}
$$

The partial pressure of oxygen can be "automatically" increased in the heating-up phase of the growth process by the thermal decomposition of carbon dioxide in reaction (7). Temperature dependence of $\mathrm{PO}_{2}$ with comparing different gases in this reaction is shown in Figure 5.

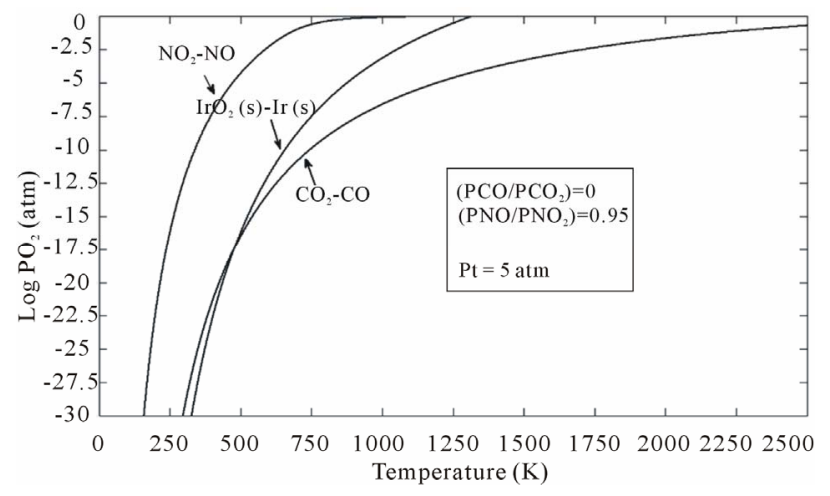

Figure 5. Temperature dependence of $\mathrm{PO}_{2}$ within different gas mixtures comparing the stability regions for iridium (iridium metal and its solid oxide).

Using $\mathrm{CO}_{2}$ at a total pressure of approximately 10 bars, Ganschow et al. [27] have successfully grown $\mathrm{ZnO}$ crys tals from the melt in a Bridgman-like configuration.

\section{2. $\mathrm{NO}_{2}$-NO System}

Similar to $\mathrm{CO}_{2}-\mathrm{CO}$ system, the partial pressure of oxygen in $\mathrm{NO}_{2}$ - $\mathrm{NO}$ system can be determined by establishing the reaction

$$
2 \mathrm{NO}_{2}=2 \mathrm{NO}+\mathrm{O}_{2}
$$

The oxygen partial pressure in $\mathrm{NO}_{2}$ - $\mathrm{NO}$ gaseous atmosphere in various temperatures is illustrated in Figure 5. In $\mathrm{NO}_{2}$-NO system, the released oxygen is too much at low temperatures in comparison with other gaseous components like $\mathrm{CO}_{2}-\mathrm{CO}$ or $\mathrm{H}_{2} \mathrm{O}-\mathrm{H}_{2}$. Therefore, the crucible indeed would be oxidized.

\section{3. $\mathrm{CO}_{2}-\mathrm{NO}-\mathrm{CO}-\mathrm{NO}_{2}$ System}

It is obvious that, by mixing $\mathrm{CO}_{2}, \mathrm{NO}, \mathrm{CO}$ and $\mathrm{NO}_{2}$, partial pressure of $\mathrm{O}_{2}$ can be provided by establishing the reaction

$$
\mathrm{CO}_{2}+\mathrm{NO}=\mathrm{CO}+\mathrm{NO}_{2}
$$

According to Figure 6, $\mathrm{NO}_{2}-\mathrm{NO}$ and $\mathrm{CO}_{2}-\mathrm{CO}$ gas mixtures can be used when very low partial pressure of oxygen is required at relatively low temperatures in order to suppress oxidation of iridium crucible. They can be also utilized when high partial pressure of oxygen is required at elevated temperature for the stabilization of $\mathrm{ZnO}$ associated with prevention from iridium oxidation. In this case, the oxygen partial pressure of chamber at $P_{t}$ $=5 \mathrm{~atm}$ should be larger than $\left(\mathrm{PO}_{2}\right)_{\min }=0.177 \mathrm{~atm}$ to have $\mathrm{ZnO}$ melt. In order to suppress the oxidation of iridium crucible, the $\mathrm{PO}_{2}$ of system should be less than $\left(\mathrm{PO}_{2}\right)_{\max }$. From Table 2, $\mathrm{NO}_{2}-\mathrm{NO}$ and $\mathrm{CO}_{2}-\mathrm{CO}$ gas mixtures in the certain molar ratio can be used for $\mathrm{ZnO}$ crystal growth at $5 \mathrm{~atm}$ total pressure.

The researches on growth of $\mathrm{ZnO}$ single crystals by 


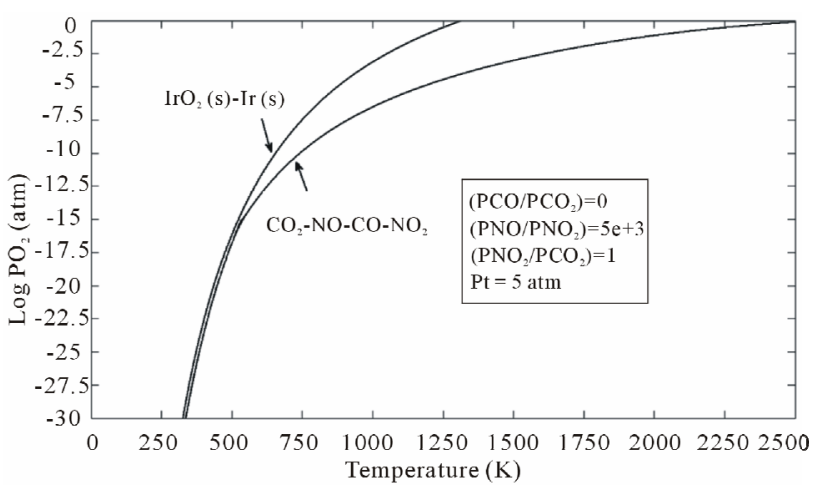

Figure 6. Temperature dependence of $\mathrm{PO}_{2}$ within $\mathrm{CO}_{2}$-NO$\mathrm{CO}-\mathrm{NO}_{2}$ gas mixtures compared with stability regions for iridium (iridium metal and its solid oxide).

Table 2. Maximum, minimum and equilibrium $\mathrm{PO}_{2}$ that is supplied by different gas mixtures at 5 atm total pressure in different temperatures obtained from Figures 5 and 6.

\begin{tabular}{cccccc}
\hline & \multicolumn{5}{c}{$\mathrm{PO}_{2}(\mathrm{~atm})$} \\
\cline { 2 - 6 } $\begin{array}{c}\text { Temprature } \\
(\mathrm{K})\end{array}$ & $\left(\mathrm{PO}_{2}\right) \mathrm{min}$ & $\begin{array}{c}\left.\mathrm{PO}_{2}\right) \text { eq } \\
\mathrm{CO}-\mathrm{CO}_{2}\end{array}$ & $\begin{array}{c}\left(\mathrm{PO}_{2}\right) \text { eq } \\
\mathrm{NO}^{-\mathrm{NO}_{2}}\end{array}$ & $\begin{array}{c}\left(\mathrm{PO}_{2}\right) \text { eq } \\
\mathrm{CO}_{2}-\mathrm{NO}_{2-} \\
\mathrm{CO}-\mathrm{NO}\end{array}$ & $\begin{array}{c}\left(\mathrm{PO}_{2}\right) \\
\text { max } \\
(\text { iridium })\end{array}$ \\
\hline 800 & $5.37 \times 10^{-36}$ & $8.77 \times 10^{-10}$ & 0.40 & $9.31 \times 10^{-10}$ & $4.0 \times 10^{-7}$ \\
2248 & 0.177 & 0.074 & - & 0.29 & - \\
\hline
\end{tabular}

the Czochralski method were carried on until now. However, all attempts to obtain crystallization of bulk $\mathrm{ZnO}$ are failed and only polycrystalline $\mathrm{ZnO}$ solidified on the iridium seed rod has been reported [11]. Control on the Czochralski experiments are failed, as the evaporation rate of $\mathrm{ZnO}$ at the melting point is high, even under the pressures applied up to $20 \mathrm{~atm}$. However, the partial pressure of $\mathrm{O}_{2}$ at total pressure of $20 \mathrm{~atm}$ that is supplied by pure $\mathrm{CO}_{2}$ barely reaches to $1.89 \times 10^{-1}$ atm at the melting point of $\mathrm{ZnO}$ crystal.

Based on Table 2, the oxygen partial pressure of gas mixtures containing $\mathrm{CO}_{2}-\mathrm{NO}-\mathrm{CO}-\mathrm{NO}_{2}$ with $\left(\mathrm{NO} / \mathrm{NO}_{2}\right)=$ $5 \times 10^{3}$ and $\left(\mathrm{CO} / \mathrm{CO}_{2}\right)=0$ reaches to $\mathrm{PO}_{2}=0.29 \mathrm{~atm}$ at $\mathrm{ZnO}$ melting point. It would be concluded that, the $\mathrm{ZnO}$ crystal growth can be performed from the melt at lower total pressures $(<5 \mathrm{~atm})$ compared with $\mathrm{CO}-\mathrm{CO}_{2}$ system (>20 atm).

\section{Conclusions}

A thermodynamic analysis performed in this study shows that the growth of $\mathrm{ZnO}$ bulk crystals from the melt at $2248 \mathrm{~K}$ should be possible in iridium crucible. During the crystal growth, appropriate partial pressure of $\mathrm{O}_{2}$ in the chamber is needed to keep the growth process possible. On the other hand, the partial pressure of $\mathrm{O}_{2}$ should be kept adequately low at relatively low temperatures to suppress the oxidation of constructive parts specially the crucible.
The best practical solution to this problem is utilizetion of $\mathrm{CO}_{2}-\mathrm{NO}-\mathrm{CO}-\mathrm{NO}_{2}$ in the growth atmosphere. According to the thermodynamic calculations, the amount of $\mathrm{PO}_{2}$ supplied by $\mathrm{CO}_{2}-\mathrm{NO}-\mathrm{CO}-\mathrm{NO}_{2}$ is sufficient to stabilize the molten oxide and low enough to allow the use of iridium crucible. It is worthy to note that the $\mathrm{ZnO}$ crystal growth can be performed from the melt (Czochralski and Bridgman techniques) at lower total pressure compared with $\mathrm{CO}-\mathrm{CO}_{2}$ system.

\section{REFERENCES}

[1] C. Liu, F. Yun and H. Morkoc, "Ferromagnetism of $\mathrm{ZnO}$ and GaN: A Review," Journal of Materials Science: Materials in Electronics, Vol. 16, No. 9, 2005, pp. 555-597.

[2] T. Muranaka, Y. Kikuchi, T. Yoshizawa, N. Shirakawa and J. Akimitsu, "Superconductivity in Carrier-Doped Silicon Carbide," Science and Technology of Advanced Materials, Vol. 9, No. 4, 2008, p. 8. doi:10.1088/1468-6996/9/4/044204

[3] A. Janotti and C. G. Walle, "Fundamentals of Zinc oxide as a Semiconductor," Reports on Progress in Physics, Vol. 72, No. 12, 2009, p. 29. doi:10.1088/0034-4885/72/12/126501

[4] T. Fukuda and D. Ehrentraut, "Prospects for the Ammonothermal Growth of Large GaN Crystal," Journal of Crystal Growth, Vol. 305, No. 2, 2007, pp. 304-310. doi:10.1016/j.jcrysgro.2007.04.010

[5] M. M. C. Chou, L. Chang, H. Y. Chung, T. H. Huang, J. $\mathrm{Wu}$ and $\mathrm{C}$. W. Chen, "Growth and Characterization of Nonpolar ZnO Epitaxial Film on $\gamma-\mathrm{LiAlO}_{2}$ Substrate by Chemical Vapor Deposition," Journal of Crystal Growth, Vol., 308, No. 2, 2007, pp. 412-416. doi:10.1016/j.jcrysgro.2007.08.019

[6] S. J. Pearton , D. P. Norton, K. Ip, Y.W. Heo and T. Steiner, "Recent Progress in Processing and Properties of ZnO," Progress in Materials Science, Vol. 50, No. 3, 2005, pp. 293-340. doi:10.1016/j.pmatsci.2004.04.001

[7] R. Triboulet, "International Conference on Solid State Crystals 2000: Growth, Characterization and Applications of single crystal," SPIE, Vol. 4412, Poland, 2001.

[8] D. M. Bagnall, Y. F. Chen, Z. Zhu, T. Yao, M. Y. Shen and T. Goto, "High Temperature Excitonic Stimulated Emission from ZnO Epitaxial Layers," Applied Physics Letters, Vol. 73, No. 8, 1997, pp. 1038-1041. doi.org/10.1063/1.122077

[9] J. Cheng, R. Guo and Q. M. Wang, "Zinc Oxide SingleCrystal Microtubes," Applied Physics Letters, Vol. 10, No. 24, 2004, pp. 5140-5143. doi:10.1063/1.1825067

[10] D Klimm, D Schulz and S Ganschow," Growth of Bulk ZnO," Comprehensive Semiconductor Science and Technology, Vol. 3, 2011, pp. 302-338. doi:10.1016/B978-0-44-453153-7.00095-X

[11] D. Klimm, S. Ganschow, D. Schulz and R. Fornari, "The Growth of ZnO Crystals from the Melt," Journal of Crystal Growth, Vol. 310, No. 12 2008, pp. 3009-3013. doi:10.1016/j.jcrysgro.2008.02.027 
[12] Suscavage, M. Harris, D. Bliss, P. Yip, S. Q. Wang, D. Schwall, L. Bouthillette, J. Bailey, M. Callahan, D. C. Look, D. C. Reynolds, R. L. Jones and C. W. Litton, "High Quality Hydrothermal ZnO Crystals," Journal of Nitride Semiconductor Research, Vol. 537, 1998. doi:10.1557/PROC-537-G3.40

[13] D. C. Look, D. C. Reynolds, C. W. Litton, R. L. Jones, D. B. Eason and G. Cantwell, "Characterization of Homoepitaxial p-Type ZnO Grown by Molecular Beam Epitaxy," Applied Physics Letters, Vol. 81, No. 10, 2002, pp. 1830-1833. doi:10.1063/1.1504875

[14] E. Ohshima, H. Ogino, I. Niikura, "Growth of the 2-in-Size Bulk ZnO Single Crystals by the Hydrothermal Method," Journal of Crystal Growth, Vol. 260, No. 1-2, 2004, pp.166-170. doi:10.1016/j.jcrysgro.2003.08.019

[15] K. Maeda, M. Sato, I. Niikura and T. Fukuda, "Growth of 2 Inch ZnO Bulk Single Crystal by the Hydrothermal Method," Semiconductor Science and Technology, Vol. 20, No. 4, 2005, p. 49. doi:10.1088/0268-1242/20/4/006

[16] Ehrentraut, H. Sato, Y. Kagamitani, H. Sato, A. Yoshikawa and T. Fukuda, "Solvothermal Growth of $\mathrm{ZnO}$," Progress in Crystal Growth and Characterization of Materials, Vol. 52, No. 4, 2006, p. 280. doi:10.1016/j.pcrysgrow.2006.09.002

[17] B. J. Coppa, C. C. Fulton, S. M. Kiesel, R. F. Davis, C. Pandarianth, J. E. Burnette, R. J. Nemanich and D. J. Smith, "Structural, Microstructural, and Electrical Properties of Gold Films and Schottky Contacts on Remote Plasma-Cleaned, n-Type $\mathrm{ZnO}\{0001\}$ Surfaces," Journal of Applied Physics, Vol. 97, No. 10, 2005, Article ID: 103517. doi: $10.1063 / 1.1898436$

[18] K. Jacobs, D. Schulz, D. Klimm and S. Ganschow, "Melt Growth of ZnO Bulk Crystals in Ir Crucibles," Solid State Sciences, Vol. 12, No. 3, 2009, pp. 307-310. doi:10.1016/j.solidstatesciences.2009.05.015

[19] J. Nause and B. Nemeth, "Pressurized Melt Growth of ZnO Boules," Semiconductor Science and Technology,
Vol. 20, No. 4, 2005, p. 45. doi:10.1088/0268-1242/20/4/005

[20] D. R. Gaskell, "Introduction to the Thermodynamics of Materials," 4th Edition, Taylor \& Francis, New York, 2003.

[21] H. J. T. Elingham, "Industrial Applications of Electrolysis," Journal of the Society of Chemical Industry, Vol. 63, No. 5, 1944, p. 125. doi:10.1002/jctb.5000630501

[22] M. Binnewies and E. Milke, "Thermochemical Data of Elements and Compounds," 3rd Edition, Wiley-VCH Verlag GmbH, Weinheim, 2008.

[23] R. Weiland, D. F. Lupton, B. Fischer, J. Merker, C. Scheckenbach and J. Witte, "High-Temperature Mechanical Properties of the Platinum Group Metals," Platinum Metals Review, Vol. 50, No. 4, 2006, pp. 158-170. doi: $10.1595 / 147106706 \times 154198$

[24] Z. Galazka, R. Uecker, K. Irmscher, M. Albrecht, D. Klimm, M. Pietsch, M. Brützam, R. Bertram, S. Ganschow and R. Fornari, "Czochralski Growth and Characterization of $\beta-\mathrm{Ga}_{2} \mathrm{O}_{3}$ Single Crystals," Crystal Research and Technology Vol. 45, No. 12, 2010, pp. 1229-1236. doi:10.1002/crat.201000341

[25] M. Asadian, N. Mirzaei, H. Saeedi, M. Najafi and I. M. Asl, "Improvement of Nd:GGG Crystal Growth Process under Dynamic Atmosphere Composition," Solid State Sciences Vol. 14, No. 2, 2012, pp. 262-268. doi:10.1016/j.solidstatesciences.2011.11.030

[26] W. Hornfeck, S. Freistein and B. Harbrecht, " $\mathrm{Ir}_{7} \mathrm{Zn}_{19}$ and $\mathrm{IrZn}_{3}$, Two New $\gamma$-Brass-Related Phases Classified as $\mathrm{AlB}_{2}$-Type Derivatives with Ordered Vacancies," Zeitschrift für Anorganische und Allgemeine Chemie, Vol. 630, No. 19, 2004, p. 1370.

[27] S. Ganschow, D. Schulz, D. Klimm, R. Bertram and R. Uecker, "Application of Predominance Diagrams in Melt Growth of Oxides," Crystal Research and Technology Vol. 45, No. 12, 2010, pp. 1219-1224. doi: $10.1002 /$ crat.201000358 